\title{
Antimicrobial Potential of Vapour Phase Acetic Acid in Combination with Ethyl Alcohol against Salmonella Typhimurium Contaminated on Bird Eye Chili (Capsicum frutescens L.)
}

\author{
Pasit Nichayapun ${ }^{1}$, Theeraporn Khawsa-ard ${ }^{1}$, Todsaphon Pimrat ${ }^{1}$, Pokpong Lilitsajja ${ }^{1}$, and Racha Tepsorn ${ }^{1, *}$ \\ ${ }^{1}$ Food Science and Technology Division, Faculty of Science and Technology, Thammasat University (Rangsit Centre), Phathum Thani, \\ Thailand
}

\begin{abstract}
Bacterial contamination is the main cause of food poisoning. The currently decontamination methods arise to find novel, effective and safe approach. Acetic acid (AC) in both aqueous and vapour forms have been conducted on its effectiveness against several bacterial contaminations. The use in high concentration can cause strong smell and corrosives that have an effect on the qualities of food. This study aim to assess the potential of Mechanically Vapourized AC solution in combination with ethyl alcohol (EA) (MVA-E) on the reduction of Salmonella enterica serotype Typhimurium ATCC 13311 contaminated on both microbiological media and on fresh Bird Eye Chili (Capsicum frutescens L.). In vitro surface inhibitions of $S$. Typhimurium at low population, ca. $1.0 \mathrm{CFU} / \mathrm{cm}^{2}$, and high population, ca. $10.0 \mathrm{CFU} / \mathrm{cm}^{2}$ were examined on Tryptic Soya Agar (TSA). MVA-E at the concentration of 10:95 (AC:EA) presented the absolutely inhibited S. Typhimurium within 20 min at $27 \pm 2^{\circ} \mathrm{C}$. At the concentration of 10:75 (AC:EA), the absolutely inactivated S. Typhimurium was observed within $10 \mathrm{~min}$ at $50 \pm 2^{\circ} \mathrm{C}$. For the evaluation of antimicrobial activity of MVA-E over time, the results indicated that ca. $8.00 \log _{10}$ reductions were observed within 20,25 and $25 \mathrm{~min}$ at the concentration of AC:EA ratio as 10:95, 10:75, and 10:45, respectively at $27 \pm 2^{\circ} \mathrm{C}$. The effectiveness of MVA-E increased when the temperature of MVA-E process increased. The reduction of $S$. Typhimurium contaminated on fresh Bird Eye Chili by MVA-E was also determined at $4{ }^{\circ} \mathrm{C}, 27 \pm 2^{\circ} \mathrm{C}$ and $50^{\circ} \mathrm{C}$. The efficiency of MVA-E on the reduction of S. Typhimurium depended on the concentration of EA in MVA-E process, the fumigation time and also the temperature. To the best of knowledge this is the first time a combination of AC and EA in vapour phase has been tested as a preservative method prevent microorganism proliferation.
\end{abstract}

\section{Introduction}

Chilies (Capsicum sp.) have been cultivated in many regions of the world [1]. One of the most consumed chili in Thailand is Brid Eye Chili, (Capsicum frutescens L.), a wide range of chili fruits is available in ASEAN's markets [2]. It was used as pungent ingredients in several culinary practices [3]. Also it is green ingredient used to prepare several meals, some people consume as fresh fruit. Chilies, such as Bird Eye Chili are often contaminated by microorganisms on the surface and can cause food poisoning illness [4-7]. The outbreaks caused by consumptions of contaminated those with foodborne pathogens as Salmonella sp., Listeria monocytogenes, Vibrio sp. or others [8-10]. As a consequence of such situation, contaminations of Salmonella sp. in vegetables become the greatest for public health concerns. Postharvest handling such as washing or spraying with sanitizer is most important procedure in view of the fact that removed, eliminated or reduced the surface microbiological contaminant. The US-FDA suggested the use of $200 \mathrm{mgL}^{-1}$ chlorine, at a $\mathrm{pH}$ of $6.0-7.5$, for $1-2$ min as disinfection processes for fresh produce. Several reports had indicated that chlorine at that level lacks the effectiveness to eliminate spoilage microorganisms. In addition, chlorine presented the potential to form carcinogenic compounds [11]. Several researchers have projected other sanitization processes [12-13]. Among of those, AC presented the special interest [14-15]. Volatile antimicrobial have become popular in research and have also been exhibited antimicrobial properties in many food product [14, 16-18]. The use of acetic AC in vapour phase was reported about their potential to control the growth of microorganism. However, the use of AC alone in vapour phase caused the strong vinegar odour and affected to the appearance quality of vapourized fresh produces. The use of volatile antimicrobial substances such as EA or in combination with another should be the good alternative technique. Thus, in this study the efficacy of mechanically vapourized AC (MVA) in combination with mechanically vapourized EA (MVE) as mechanically vapouized AC-EA (MVA-E) on the

\footnotetext{
Corresponding author: rtepsorn@tu.ac.th
} 
reduction of $S$. Typhimurium in both in vitro study and contaminated on model fresh Bird Eye Chili was investigated.

\section{Materials and Methods}

\subsection{Chemical and microbiological media}

Tryptic Soya Agar (TSA), Tryptic Soya Broth (TSB) and Peptone were purchased from Difco (Dico, USA). AC was purchased from QRëC (QRëC, New Zealand). 95\% EA was kindly provided by The Liquor Distillery Organization of Thailand.

\subsection{Preparation of Test Organism}

S. Typhimurium, was kindly provided by Department of Food Science and Technology, Thammasat University (Rangsit Centre). Period of expose, $S$. Typhimurium was sub-culture twice in TSB at $37^{\circ} \mathrm{C}$ for $18 \mathrm{~h}$ before use as inocula.

\subsection{In vitro susceptibility of $S$. Typhimurium to the MVA-E}

\subsubsection{Agar overlay method}

The susceptibility of $S$. Typhimurium to MVA-E was determined in vitro using modified agar overlay method. Briefly, The $S$. Typhimurium at $c a$. $7.0 \log _{10} \mathrm{CFU} / \mathrm{mL}$ was used as high inoculums and at ca.4.00 $\log _{10}$ $\mathrm{CFU} / \mathrm{mL}$ as low inoculum. Contaminated Petri dishes without cover were aseptically placed in fumigation chamber as presented in Fig. 1. AC solution at the concentration of $10.0 \%$ in combination with EA at the concentration of $0 \%, 30.0 \%, 45.0 \%, 75.0 \%$ and $95.0 \%$ was individually placed and directly connected with air pump.

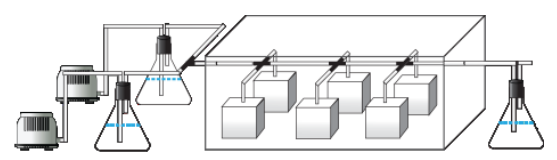

Fig. 1. Schematic illustration represented the fumigation chamber

Plates were contacted with MVA-E and withdrew at the interval time as $0,5,10,15,20$ and $10 \mathrm{~min}$. The reduction ratio was calculated after incubation. The impact of temperature was determined at $4^{\circ} \mathrm{C}$ and $50^{\circ} \mathrm{C}$. The rate of vapour production was calculated.

\subsubsection{Time killing analysis}

For time killing analysis, the susceptibility of $S$. Typhimurium to MVA-E was determined in vitro. $S$. Typhimurium at $c a$. $8.00 \log _{10} \mathrm{CFU} / \mathrm{mL}$ was prepared in $50 \mathrm{~mL}$ TSB. Fumigation tube connected with MVA-E was aseptically placed into suspension. MVA-E was generated. At the interval time as $0,5,10,15,20$ and 25 min the microbial populations were enumerated by spread plate technique on TSA. As described above, the impact of temperature was also determined.

\subsection{MVA-E effects on fresh Bird Eye Chili inoculated with $S$. Typhimurium}

\subsubsection{S. Typhimurium suspension preparation}

$S$. Typhimurium was sub-cultured twice in TSB. Cells were harvested by centrifugation at $1000 \mathrm{xg}$ for $15 \mathrm{~min}$ at $4^{\circ} \mathrm{C}$. The inocula was adjusted to the final concentration at $c a 7.00-8.00 \log _{10} \mathrm{CFU} / \mathrm{mL}$

\subsubsection{Challenging Test}

Bird Eye Chilies were purchased from local markets near Thammasat University. Each fruit was sanitized in 1000 ppm chlorinated water. The fruits were dry under UV lamp. $0.1 \mathrm{~mL}$ of prepared $S$. Typhimurium was contaminated on each to obtain $6.00 \mathrm{Log}_{10} \mathrm{CFU} / \mathrm{g}$. The contaminated those were then exposed to MVA-E in the fumigation chamber at $65 \pm 2 \% \mathrm{RH}$. Each fumigated fruit was then examined for evidence of survival of $S$. Typhimurium by spread plate technique. The population of organism was calculated as $\log _{10} \mathrm{CFU} / \mathrm{g}$. The impact of temperature was also determined.

\section{Results and Discussions}

\subsection{Susceptibility of $S$. Typhimurium to MVA-E}

\subsubsection{In vitro agar overlay method}

Efficacies of MVA-E against $S$. Typhimurium on the surface of TSA are demonstrated in Fig. 2. The results presented the inhibitory effect of MVA-E against $S$. Typhimurium at $95.0 \%$ and $75.0 \%$ of EA in combination with $10.0 \% \mathrm{AC}$ at $27 \pm 2{ }^{\circ} \mathrm{C}$ within 20 and $25 \mathrm{~min}$, respectively. At the low concentration, the complete destructive effect was not detected. These inhibitory properties were detected in both low and high inoculums level. As shown, the temperature affected the antimicrobial properties of MVA-E. At low temperature $\left(4^{\circ} \mathrm{C}\right)$, the efficacy of MVA-E was decreased compared with room temperature $\left(27 \pm 2^{\circ} \mathrm{C}\right)$, and increased when exposed with high temperature as $50^{\circ} \mathrm{C}$. According to Fig 3, the increasing rate of $\mathrm{pH}$ and weight loss of both $\mathrm{AC}$ and EA under vaporized process were the main factors affecting the antimicrobial properties. These increasing were obviously presented when those were exposed to high temperature. Hence, $\mathrm{pH}$ of test solution and weight loss of $\mathrm{AC}$ and EA increased along with the rising of temperature, the antimicrobial properties of MVA-E also increased when the temperature increased. As mentioned in the previous research, the inhibition potential of $\mathrm{AC}$ was acted upon the $\mathrm{pKa}$ and $\mathrm{pH}[20,21]$. The bacteriostatic and bactericidal of $\mathrm{AC}$ and the other 
derivatives have been attributed to the lower $\mathrm{pH}$ below $\mathrm{t}$

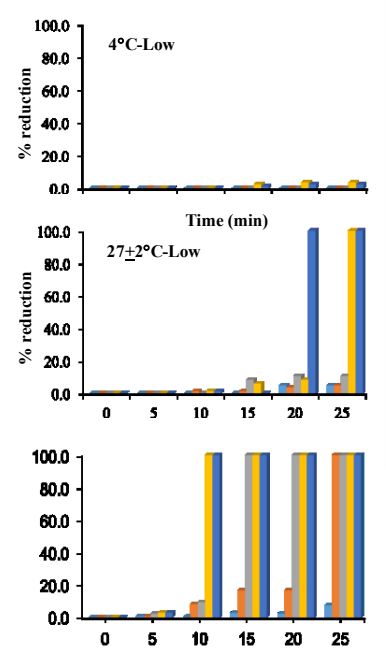

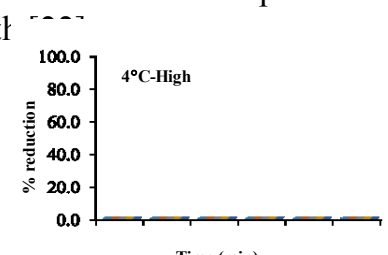
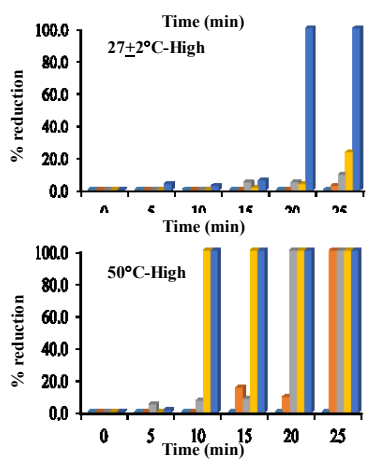

Fig. 2. Reduction of $S$. Typhimurium on contaminated TSA during the fumigation with MVA-E and different concentration of EA ("; 0\%, "; 30\%, - 45\%, "; 75\%, "; 95\%)

The $\mathrm{pH}$ affected the survival of Salmonella sp. was 4.9 [23]. As a result, the $\mathrm{pH}$ of MVA-E was nearly3.0 it was in range of inhibition. Therefore, the confirmation of $S$. Typhimurium inhibition by MVA-E was subjected to the decreasing of $\mathrm{pH}$.
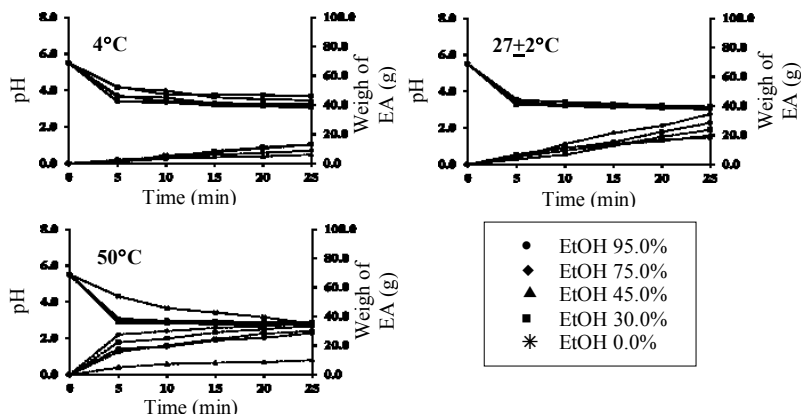

Fig. 3. The change in weight of EA and $\mathrm{pH}$ during fumigation.

The other possibility of the impact of temperature on the antimicrobial properties of MVA-E is that the upsurge in dissociated molecules. The proton motive activity of the outer membrane might be interfered, and then resulted to penetration of the undissociated form of $\mathrm{AC}$. For this reason, intracellular $\mathrm{pH}$ was reduced and inducing cell death. EA demonstrated the assist properties. It changed the properties of outer membrane. Because of the fact that, Phospholipid, the main component of cell membrane, was dissolved by EA and caused the damage, $\mathrm{AC}$ in both undissociated and dissociated form could simply penetrate into cell and caused the death of cell. Glycoprotein, the protein component of cell membrane, was denaturized by EA and also caused the nonsurvivable of cell.

\subsubsection{Time killing analysis}

In Fig. 4 the Time Killed-Curve, represented the antimicrobial activity of MVA-E were shown. The

MVA-E at the concentration of EA at 45.0, 75.0 and $95.0 \%$ had no ability to provide the lethal effect within $15 \mathrm{~min}$. However, $S$. Typhimurium was reduced to undetectable level within more than 20 min when the above mentioned concentrations of EA in MVA-E were used.

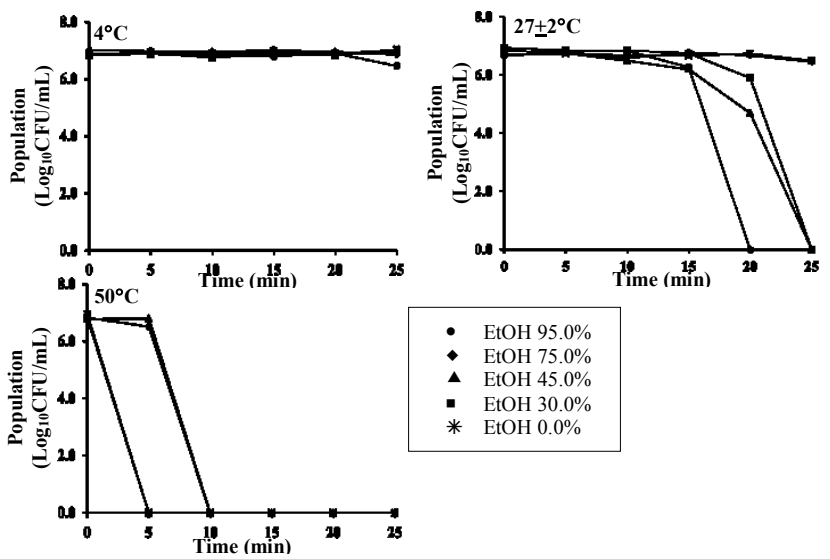

Fig. 4. The population of $S$. Typhimurium during contact with MVA-E at different concentration of EA

The temperature demonstrated the effect on antimicrobial properties of MVA-E. At the higher temperature, the antimicrobial activity was greater than at the low temperature. The time killing analysis is equal to the inhibition curve, known as the 'killing curve'. In generally, this studies showed that the survivors of those was decreased by concentration of EA was increased, and completely inhibited at the concentration more than $45.0 \%$. Moreover, it could be indicated that the longer the fumigation time the lower the necessary concentration of the MVA-E. The Time-Dependent characteristic was observed according to this study.

\subsection{MVA-E effects on fresh Bird Eye Chili inoculated with $S$. Typhimurium}

\subsubsection{Challenging Test}

The initial amount of contaminated $S$. Typhimurium on Bird Eye Chili at $c a$. $6.00 \log _{10} \mathrm{CFU} / \mathrm{g}$ were exposed to MVA-E at the concentration of $\mathrm{AC}$ at $10.0 \%$ in combination with the different concentration of EA along with different fumigation time.

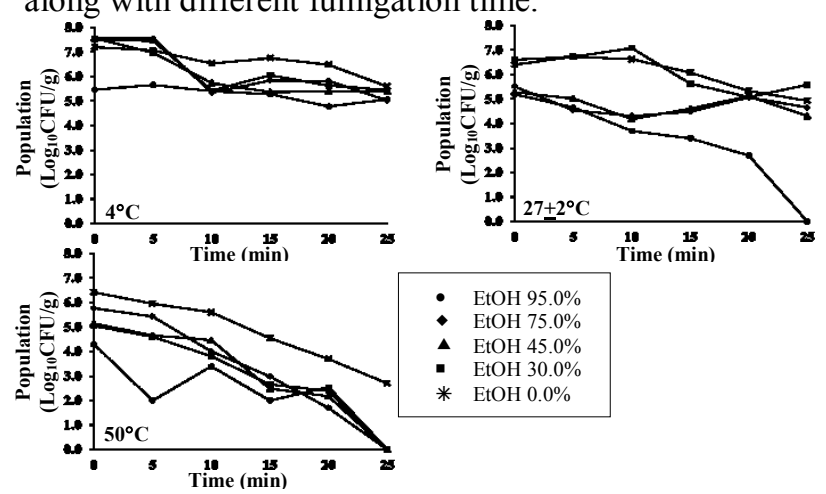

Fig. 5. Reduction of $S$. Typhimurium contaminated on Bird Eye Chili as affect by MVA-E at different EA concentration. 
The effect of operating temperature was also determined. The results were shown in Fig. 5. The natural contaminated Bird Eye Chilies were also tested. The numbers of Total Bacteria Count (TBC) were determined as describe above. The results of TBC were presented in Fig 6. Fumigation with MAV-E at room temperature $\left(27 \pm 2^{\circ} \mathrm{C}\right)$ and $50^{\circ} \mathrm{C}$ at all concentration of EA demonstrated the lethal effect. At the concentration of $\mathrm{AC}$ at $10.0 \%$ in combination with $95.0 \%$ EA the complete destruction was presented within $25 \mathrm{~min}$. When the temperature decreased to $4^{\circ} \mathrm{C}$ the complete elimination was not detected along the period of fumigation. The downward trend of fumigation time was observed when the temperature was rising. Weak acid always demonstrate the microbial inhibition properties [19-20].
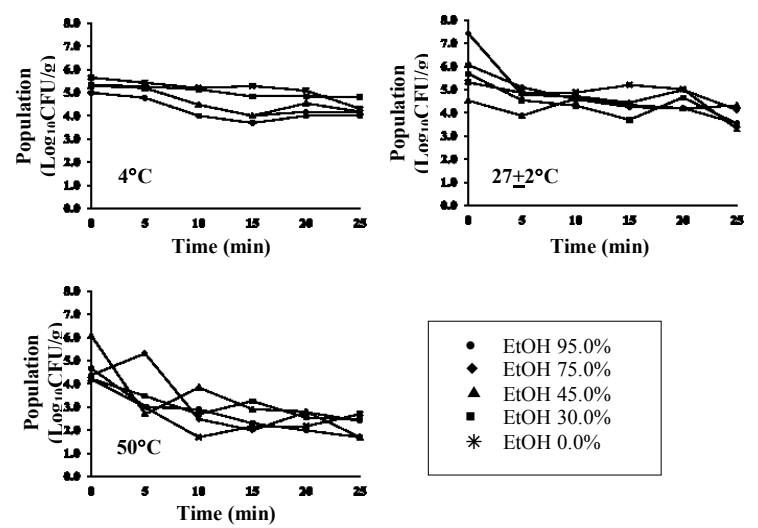

Fig. 6. Reduction of Total bacteria count contaminated on Bird Eye Chili as affect by MVA-E at different EA concentration.

Consideration on the effective of MVA-E against natural contaminated microorganism on Bird Eye Chili, it could be indicated that the complete elimination was not detected within the period of exposure.

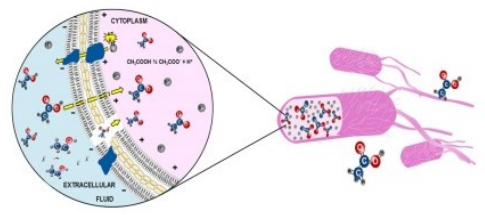

Fig. 7. Schematic illustration of the possible mechanism of MVA-E against $S$. Typhimurium

As presented in Fig. 7, the possible antimicrobial mechanism of MVA-E was demonstrated. It seems that MVA-E decontaminates surfaceborne microorganism and thus sterilizes vegetable surfaces [24]. In this research, the results demonstrated that MVA-E presented the inhibitory effect on both $S$. Typhimurium in vitro and in model food as Bird Eye Chilis. The mechanically vapourized process allowed the $\mathrm{AC}$ in the form of dissociated to become the undissociated molecule in vapour phase. For this reason, the MVA-E presented more inhibitory properties. Another advantage, the gas phase can diffuse much more than liquid phase so the rate of cell membrane penetration become more rapid compared to liquid phase.
Mechanically vapourized AC in combination with EA (MVA-E) presented the inhibitory potential to eliminate and decontaminate the number of $S$. Typhimurium in both in vitro and model food as contaminated on fresh Bird Eye Chilies. It is free of carcinogenic risk. The antimicrobial properties depended on the concentration, fumigation time and the temperature. When these key factors increase, the antimicrobial properties are also increased.

\section{References}

1. K.H., Kraft, C.H., Brown, G.P., Nabhan, E., Luedeling, J.J., Luna-Ruiz, G.C., d'Eeckenbrugge, R.J., Hijmans, P., Gepts. PNAS, 111 (2014)

2. Servicio de Información Agroalimentaria y Pesquera. Secretaría de Agricultura, Ganadería, Desarrollo rural, Pesca y Alimentación (SIAP). Cierre de la producción agrícola por cultivo, (2015)

3. NC., Elviss, C.L., Little, L., Hucklesby, S., Sagoo, S., Surman-Lee, E. de Pinna, E.J., Threlfall. Int J Food Microbiol., 134, (2009)

4. J.M., Farber. J Food Prot., 60, (1997)

5. M.M.I., Osornio, A.R., Chaves., J Food Prot., 60, (1997)

6. G.A., Francis, C., Thomas, D., O'Breine., Int J Food Sci Technol., 34, (1999).

7. A.M., Piagentini, E.M., Pirovani, D.R., Güemes, J.H., di Pentima, M.A., Tesisi., J. Food Sci., 62, (2006)

8. M., Friedman, P.R., Henika, R.E., Mandrell., J Food Prot., 65, (2002).

9. L., Pezzoli, R., Elson, C.L. Little, H., Yip, I., Fisher, R., Yishai, J., Threfall., Foodborne Pathog Dis., 5, (2008)

10. J., Pakalniskiene, G., Falkenhorst, M., Lisby, S.B., Madsen, K.E., Olsen, E.M. Nielsen, K., Mølbak., Epidemiol Infect, 137, (2009)

11. M.E., Parish, L.R., Beuchat, T.V., Suslow, L.J., Harris, E.H., Garrett, J.N., Farber, F.F., Busta., Compr. Rev. Food Sci. and Food Saf. 2, (2003)

12. S., Sanz, M., Giménez, C., Olarte, C., Lomas, J., Portu., J. Appl. Microbiol. 93, (2002)

13. A., Allende, J., McEvoy, Y., Tao, Y., Luo., Food Control., 20, (2009)

14. P.L., Sholberg, P., Haag, R., Hocking, K., Bedford., J. Hortic. Sci., 35, (2000)

15. B.L., Meatherall, D., Gregson, T., Ross, J.D., Pitout, K.B., Laupland, Am J Med, 122, (2009)

16. N.G., Tzortzakis., Int. J. Food Microbiol., 142, (2010)

17. M.A., Gatto, A., Ippolito, V., Linsalata, N., Cascarano, F., Nigro, S., Vanadia., Postharvest Biol. Technol., 61, (2011)

18. W., Krusong, P., Dansai, A., Itharat., KMITL Science and Technology., 12, (2012)

19. F.N., Arroyo-López, J., Bautista-Gallego, M.C., DuránQuintana, A., Garrido-Fernández., Food Microbiol., 25, (2008)

20. R.G., Bell, K.M., de Lacy., Food Microbiol., 4, (1987).

21. C., Bell, A., Kyriakides., Salmonella: A praticalapproch to the organism and its control in food, (2002)

22. J., Yeesibsan, W., Krusong, Asian Journal of Food and Agro-Industry, 2, (2009)

23. A.L., Branen, P.M., Davidson, S., Salminen., Food Additive., (1989)

24. P.L., Sholberg, A.P., Gaunce., Crop Prot., 15, (1996)

\section{Conclusions}

